\title{
Accelerate the Progress Towards Elimination of Dog-Mediated Rabies in China
}

Rabies is an ancient zoonotic disease first recorded over 4,000 years ago. Globally, over $99 \%$ of human rabies cases were caused by rabid dogs. Rabies is fatal once symptoms appear. However, rabies is preventable through mass dog vaccination and post-exposure prophylaxis (PEP), including wound treatment, vaccine injection, and passive immunization when necessary. Sustained vaccination coverage of $70 \%$ among dog populations can interrupt dogmediated rabies and is regarded as a first-line defense against human rabies for its cost-effectiveness. PEP is almost $100 \%$ effective in preventing human rabies death if carried out promptly and properly.

Rabies still affects over 150 countries and regions and caused annual human deaths of about 59,000 worldwide with about $40 \%$ of deaths occurring in individuals under 15 years old and $95 \%$ occurring in developing countries within Asia and Africa (1). India ranks at the top in the number of human rabies cases globally, and China is also one of the highest burdened countries, with several hundred human mortalities due to rabies each year (1).

Rabies also causes a heavy economic burden to both individual families and society as a whole. It is estimated that rabies had caused annual economic losses as high as 8.6 billion USD worldwide (1), while PEP only cost 1.5 billion USD in Asia yearly (1). Over $70 \%$ of human rabies cases in China were reported in rural areas. The average disposable income of China's rural population in 2020 was 17,131 CNY. PEP services cost about 300 CNY per person for injecting the vaccine alone but over 1,000 CNY if rabies immunoglobulin is needed, not including expenses of wound treatment, transportation, and delayed work. This has caused a heavy economic burden to lowincome populations in the case of dog bites.

The World Health Organization (WHO), the World Organisation for Animal Health (OIE), the Food and Agriculture Organization of the United Nations (FAO), and the Global Alliance for Rabies Control (GARC) jointly held the International Conference on the Elimination of Rabies in Geneva in December 2015 to endorse the vision of eliminating dog-mediated rabies globally by 2030 ("Zero by 2030") and jointly issued a global strategic plan in 2018 (2). "Zero by 2030" is also aligned with the United Nation Sustained Development Goal (SDG) 3 and specifically Target 3.3 (to end the epidemics ... of neglected tropical diseases) and Target 3.8 [to achieve universal health coverage ... and access to safe, effective, quality and affordable essential medicines and vaccines for all (2)].

Great progress had been made in the prevention and control of rabies in China under the coordination of all parties led by the Chinese central government in the last decade. In 2020, 202 cases were reported nationwide, affecting 143 counties and districts, which decreased by $94 \%$ and $86 \%$, respectively, compared with the peak of 3,300 cases and 984 affected counties and districts in 2007. It showed a sporadic state of rabies nationwide, which laid the foundation for the elimination of dog-mediated rabies.

In addition, as the world's second largest economy, China has institutional advantages with both a complete public health system and veterinary service system and is also capable of mass production and supply of rabies vaccines for animal and human use that meet international standards. It is therefore feasible for China to put forward the goal and road map to realize the target of rabies cases reaching "Zero by 2030".

Currently, the major challenge to achieving "Zero by 2030" in China is the management and immunization of dogs, especially in rural areas, as well as a lack of a robust and sensitive animal surveillance system and a more flexible multisector cooperative mechanism at all levels (3). In 2021, the newly revised version of the Animal Epidemic Prevention Law of the People's Republic of China was released (4), which clearly stipulates the duties of dog owners to manage and vaccinate dogs against rabies, providing a national legal guarantee for the elimination of dog-mediated rabies in China. Recent studies indicated that within China existed complex rabies transmission dynamics, including in dogs, wildlife, and livestock, which may become increasingly complicated once spread to other species, such as badgers, raccoons dogs, and foxes (5). It is also necessary to strengthen health education, as well as to promote and maintain the accessibility and standardization of PEP services in rural areas where the risk of rabies still exists. 
In this World Rabies Day Issue, we invited colleagues from China CDC, China Animal Disease Control Center, Changchun Veterinary Research Institute (National Reference Laboratory for Animal Rabies), China Institute of Veterinary Drug Control, and Tianjin CDC to report their recent studies about the progress, challenges, and opportunities of rabies control in China in the past decade. Liu ZR et al. analyzed the epidemiological characteristics of human rabies in China in the most recent five years $(\circlearrowleft)$. Feng Y et al. analyzed the epidemiological characteristics of animal rabies, including animal species, geographic distribution, and transmission sources in the past decade ( 7 ). Liu YF et al. analyzed the epidemiological characteristics of 126,133 outpatients in rabies PEP clinics in Tianjin Municipality, China in 2020 (8). Yin CS et al. reviewed the progress of development of animal rabies vaccines in China since the 1950s (9). Yin WW et al. summarized the strategies and measures, achievements, challenges, and prospect of rabies control in China (10). The findings from this issue highlighted the feasibility, necessity, and urgency to accelerate progress towards eliminating dog-mediated rabies in China and clearly outlined the next steps, i.e., based on a one health approach, focusing on dog management and immunization coverage in rural areas, as well as combatting threats from other wildlife.

doi: $10.46234 / \mathrm{ccdcw} 2021.200$ ${ }^{1}$ Division of Infectious Disease, Key Laboratory of Surveillance and Early Warning on Infectious Disease, Chinese Center for Disease Control and
Prevention, Beijing, China.

Submitted: September 19, 2021; Accepted: September 23, 2021

\section{REFERENCES}

1. Hampson K, Coudeville L, Lembo T, Sambo M, Kieffer A, Attlan M, et al. Estimating the global burden of endemic canine rabies. PLoS Negl Trop Dis 2015;9(4):e0003709. http://dx.doi.org/10.1371/journal.pntd.0003709.

2. WHO. Zero by 30: the global strategic plan to end human deaths from dog-mediated rabies by 2030. 2018. https://www.who.int/publications/i/ item/9789241513838. [2020-8-5].

3. Chen QL, Ma XY, Rainey JJ, Li Y, Mu D, Tao XY, et al. Findings from the initial Stepwise Approach to Rabies Elimination (SARE) Assessment in China, 2019. PLoS Negl Trop Dis 2021;15(3):e0009274. http://dx.doi.org/10.1371/JOURNAL.PNTD.0009274.

4. Miao FM, Li N, Yang JJ, Chen T, Liu Y, Zhang SF, et al. Neglected challenges in the control of animal rabies in China. One Health 2021;12:100212. http://dx.doi.org/10.1016/j.onehlt.2021.100212.

5. The National Peoples Congress of the People's Republic of China. Animal epidemic prevention law of the Peoples Republic of China. 2021. http://www.npc.gov.cn/npc/c30834/202101/bcedb2c057984cb680f8cc54529c0940.shtml. [2021-1-22]. (In Chinese).

6. Liu ZR, Liu M, Tao XY, Zhu WY. Epidemic characteristics of human rabies — China, 2016-2020. China CDC Wkly 2021;3(39):819 - 21. http://dx.doi.org/ 10.46234/ccdcw2021.203.

7. Feng Y, Ma JH, Sun S, Chi LJ, Kou ZY, Tu CC. Epidemiology of animal rabies - China, 2010-2020. China CDC Wkly 2021;3(39):815-8. http://dx.doi.org/10.46234/ccdcw2021.202.

8. Liu YF, Li L, Lyu J, Su C. Epidemiological study of outpatients in rabies post-exposure prophylaxis clinics — Tianjin Municipality, China, 2020. China CDC Wkly 2021;3(39):822 - 4. http://dx.doi.org/10.46234/ccdcw2021.201.

9. Yin CS. Progress in the development of animal rabies vaccines in China. China CDC Wkly 2021;3(39):825-30. http://dx.doi.org/10.46234/ ccdcw2021.204.

10. Yin WW, Fu ZF, Gao GF. Progress and prospects of dog-mediated rabies elimination in China. China CDC Wkly 2021;3(39):831 - 4. http://dx.doi.org/ $10.46234 / \mathrm{ccdcw} 2021.205$.

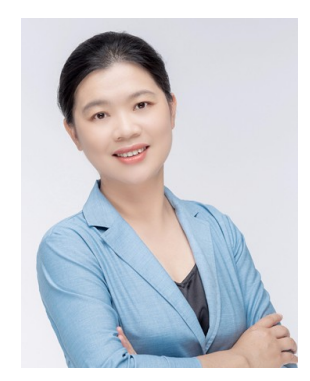

Qiulan Chen, MD, PhD

Branch Director of animal and vector-borne diseases,

Division of Infectious Disease Control,

Chinese Center for Disease Control and Prevention

Deputy Director of Rabies Working Committee,

Chinese Preventive Medicine Association 